\title{
THE ANALYSIS OF THE DYNAMICS OF TERRITORIAL STRUCTURES OF NATURAL AND ANTHROPOGENIC GEOECOSYSTEMS BY THE METHODS OF VIRTUAL SIMULATION
}

\begin{abstract}
Bogdan SHELUDCHENKO, Polissia National University, Staryi Boulevard, 7 Zhytomyr 10008 Zhytomyr Oblast, Ukraine, sheludchenkobogdan@ukr.net

Savelii KUKHARETS, Polissia National University, Staryi Boulevard, 7 Zhytomyr 10008 Zhytomyr Oblast, Ukraine, kikharets@gmail.com (corresponding author)

Jonas Č́̇SNA, Department of mechanical, energy and biotechnology engineering, Faculty of Engineering, Vytautas Magnus University, K. Donelaičio g. 58, 44248 Kaunas, Lithuania, jonas.cesna@vdu.lt

Oleksandr MEDVEDSKYI, Polissia National University, Staryi Boulevard, 7 Zhytomyr 10008 Zhytomyr Oblast, Ukraine, aleksmedvedsky@gmail.com

The structure of landscapes morphology of particular territories is characterized by the irregularity and fragmentary nature of landscape structures. The geometrical structure, which is described by some fractal dimensionality, is a generalized common property of different types of natural-territorial geoecosystems. The "supporting framework" of the territory, as its geometric model, was designed on the basis of a geomorphological description of the landscape morphology of a natural-technogenic geoecosystem. The model of the "supporting framework" of the landscape is similar to the real natural-technogenic geoecosystem and preserves its fractal dimensionality, represents the morphology of the landscape structure as well as the influence of zonal factors, geological conditions of landscape formation. The models of the "supporting framework" of the landscape are used as models- simulators of the processes of natural and anthropogenic origin when studying the dynamics of natural-technogenic geoecosystems. The analysis of the dynamics of the "supporting framework" of the natural-technogenic geoecosystem is consigned to the analysis of some virtual structure of a flat rod truss, which is loaded with forces that simulate some anthropogenic effects. This allows to optimize the permissible limits of the impact intensity of the anthropogenic component on the "supporting framework" of the natural-technogenic geoecosystem. The paper suggests a virtual studying of the "supporting framework" of the territory by the method of modeling on the principle of electrical dynamic analogies. Herewith, the currents in the electrical circuit, which simulates the set of structural elements of the "supporting framework" of the natural-technogenic geoecosystem, are analyzed. When being used at a design stage, the suggested methods of analysis allow to optimize the processes of transformation of natural-territorial complexes and ensure the maximum possible level of their ecological safety. The analytical optimization of the alternative variants of transformation of natural territorial complexes allows to reduce the levels of anthropogenic (man-made) impact on them by $15-20 \%$.
\end{abstract}

Keywords: supporting framework, territorial structure, simulation modeling, Ritter method, method of cut nodes, Kirchhoff's laws.

\section{INTRODUCTION}

It was found (Adamenko, 2014; Sheludchenko, 2014; Jongman, 2002) that the irregularity and fragmentary nature of frontal compositions of landscape structures is caused by their long-lasting development. Such structure of landscapes morphology is connected with their changes not only in space but also through time (Sheludchenko, 2014; Jongman, 2002; Vadiunyna and Korchgina, 1986). Thus, the geometrical features (including the fractal ones) are specified by the creation of natural territorial complexes (NTC). Modern compositions of NTC represent the history and the dynamics of their development.

The main genetic types of NTC, especially some particular types of landscape, were formed according to some physical-and-chemical consistent patterns. They have a generalized common property - specific geometrical structure, which is described by some fractal dimensionality (Sheludchenko, 2014). The analysis of the geometric features as well as of correlations and repetitiveness of the morphological features of NTC are the basis for the geometrical classification of the landscapes of NTC (Adamenko, 2014; Vadiunyna and Korchgina, 1986; Cook, 2002).

The results of the geological and morphological discription of a landscape structure allow to design a "supporting framework" of a territory, as its geometrical model (Adamenko, 2014; Baidikov, 2014). Some graphical interpretations of interconnections among particular landscape objects, vectors of energy and substances transfer both within the NTC as well as under the interchanging of matter and energy of the NTC with the environment (Adamenko, 2014;

Copyright (C) 2021 The Authors. Published by Vytautas Magnus University. This is an open-access article distributed under the terms of the Creative Commons Attribution License (CC BY 4.0), which permits unrestricted use, distribution, and reproduction in any medium, provided the original author and source are credited. 
Sheludchenko, 2014), except the geological and morphological discription of a landscape, can be the basis for designing a "supporting framework".

Herewith, the "supporting framewoprk" of a landscape has been compositionally structured in such a way that it is simetrical to a real NTC and keeps its fractal dimensionality. Thus, the "supporting framework" of NTC is a modelsimulator which shows the landscape structure and the effects of different factors (Li, F et al., 2015; Gorbachova, 2014). The illustration of modeling of a "simetrical net" of a natural landscape height (for its implementation in the form of a computer model-image) is given in fig. 1 (Sheludchenko, 2014).

It has been established (Loibl et al., 2007; Rouget et al., 2003) that the materalized models of "supporting frameworks" of a landscape (or their separate fragments and structural elements) can be used as model-simulators of the processes of natural and anthropogenic origin when studying the dynamics of NTC or natural technogenic geoecosystems (NTGES) by using the analogue methods - electrical dynamic and mechanical ones (Vadiunyna and Korchgina, 1986; Mordvinova et al., 2016).

If we consider the peculiarities of the formation of a "supporting framework" of a subsystem of NTGES, which is an integration of the main centers of economic and social-cultural activities (nodes) as well as of links among them in a form of a communication structure, then such a "supporting framework" is, first of all, the structure which is formed only by the main elements. A set of "framework" terms in this case includes: city framework, infrastructural framework, supporting framework of population mobility, the framework of new territories development, the framework of resources potential, ecological framework, etc. (Hussain and Imitiyaz, 2018; Gilcrease, 2013).

The nodal elements of such a supporting framework accumulate the main part of NTGES, which is oriented on meeting the society's needs. The formation of such a framework is connected with the processes which make some changes in the location of productive fecilities and their territorial structure, disregarding the peculiarities and the natural features of the framework of NTGES.

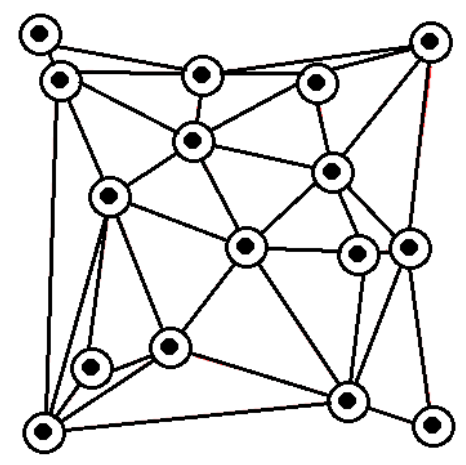

Figure 1. The model-image of a natural landscape height

The process of such frameworks formation results in a so-called "polymagistralization" of the territory: the appearance of powerful infrastructure "corridors" in which the lines of communication connections are concentrated from among particular framework nodes and gathered in one axis, along which the population and the economic sites are concentrated (fig. 2). It results in the deformation of the framework composition of NTC because of the increased contrast in population mobility, increased production concentration in the center and in the areals of concentration on the one hand, and the decrease in population in the remote areas (Hussain and Imitiyaz, 2018; Gilcrease, 2013) on the other hand.

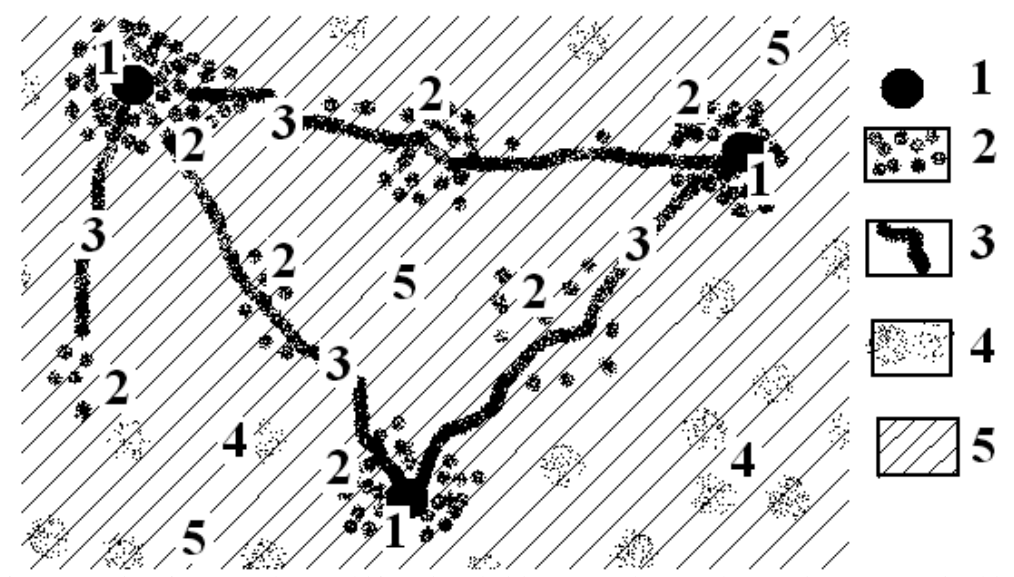

1 - cores of nodal elements of a supporting framework - multifunctional cities; 2 - urban agglomerations; 3 - major highways; 4 - administrative and economic centers of secondary importance (city-like villages and big villages); 5 - remote territories

Figure 2. Some tendences in "polymagistralization" of a supporting framework 
A so-called "framework effect" which steadily strengthens and contains three main constituent parts (Jongman, 2002; Hussain and Imitiyaz, 2018), emerges in the territorial structure of NTGES:

- the effect of agglomeration, caused by the characteristic features of a highly- urbanized territory and by the advantages of close connections;

- the effect of magistralization, caused by technical advances of transport and communication means;

- the effect of "translocations", caused by polymagistralization;

Due regard for" framework effects" is required when solving the problems of using the resource potentials of big cities.

Thus, morphological features management as well as the dynamics of the territorial structure of NTGES management require the development of reliable optimization methods (as well as ensuring the fixed levels of ecological safety). The virtuality of supporting frameworks necessiates utilizing the methods of simulation of the dynamic (or electrical dynanmic) analogies as the methods which can be used for research optimization.

That is why the purpose of research is the minimization of the anthropogenic constituent on the supporting framework of natural-technogenic geoecosystems by the model optimization of the anthropogenic impact on the naturalterritorial complexes. To achieve the goal, the next tasks were formed:

- to develop the modeling technique as well as a corresponding virtual model-image of a phase space deformation of the natural territorial complex morphology;

- to implement the techniques of mechanical-dynamic and electrical-dynamic modeling of natural anthropogenic processes in studying physical analogies of supporting frameworks of the natural-technogenic geoecosystems;

- to compare a few alternative variants of supporting framework models from the point of view of achieving a maximum possible level of ecological safety.

\section{MATERIALS AND TECHNIQUES OF THE RESEARCH}

The main results of the research were received on the basis of analitical and analogic modeling of the topographic profiles of the imitating model-images of the morphology of landscape frameworks of the natural-territorial complexes (Sheludchenko, 2014; Adamenko, 2014; Loibl et al., 2007; Mordvinova et al., 2016; Hussain and Imitiyaz, 2018).

The modeling of the process, as some function $F(t)$ of transformation of the morphology of natural-territorial complex since the moment when it was affected by some external impact, which was missing up to a particular moment (in other words, it equaled zero), and the time keeping starts since the moment of being exposed to the impact, was performed on the basis of Heaviside unit step function $H(t)$ (Sheludchenko, 2014).

The techniques of physical and dynamic simulation when using the method of calculus of vectors in statics of planar (framework) constructions - Ritter technique, the method of joints, as well as the methods of closed electric circuits optimization on the basis of Kirchhoff laws (Sheludchenko, 2014; Vadiunyna and Korchgina, 1986) were used for an analogue studying of the models.

\section{RESERCH RESULTS}

Let's consider, as an example, the schematic illustration of the territorial structure of a city agglomaration (fig. 3). The priority guidelines in the agglomeration development on the scheme are marked with arrow-heads III. If we estimate the structure of a supporting framework of NTGES according to the directions of the railroads VIII (fig. 4, $a$ ), then the virtual model of a supporting framework of the territorial agglomeration structure can be estimated as a flat truss (frame construction), whose construction is given in fig. 4,6 .

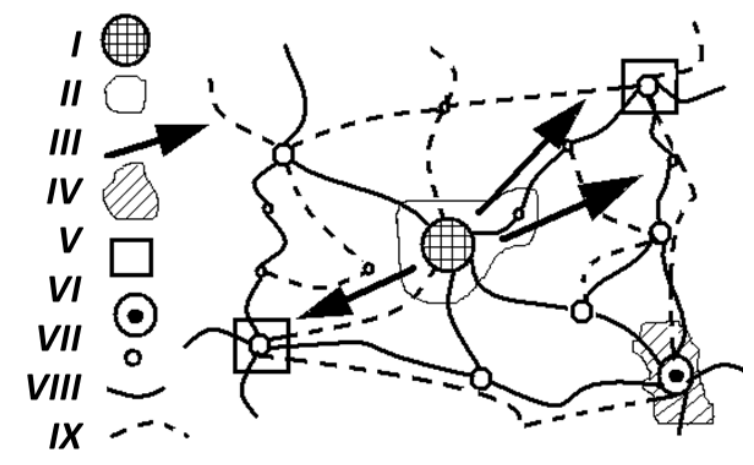

$I$ - a regulable city; $I I$ - agglomeration development; $I I I$ - directions for the development; $I V$ - priority development of "another" city; $V$ - the development of the chosen "counterweight cities"; VI-the development of centers-subdistricts; VII -stimulation of small and average-size towns; VIII - railroads; $I X$-highways

Figure 3. The dynamics of the development of a big city within an agglomeration

The directions for the development of the NTC, as some anthropogenic manifestations (marked with arrow-heads in fig. 4), are estimated as some isolated external impacts on the composition of a supporting framework model. Supposing that it is necessary to study the process $F(t)$ of the transformation of the composition of NTC structure since the moment when it 
was exposed to some external impact, which corresponds to some consistent pattern. There is a method of an analytical recording of the fact of exposing to the structure of the external imact, which was missing up to a particular moment (in other words, it equaled zero), and the time keeping starts since the moment of being exposed to the impact. To perform it, we use a so called unit function it is also called Heaviside unit step function). This function, marked $H(t)$ or $e(t)$, has a graph, given in fig. 5, that is, it equals zero under $t<0$ and it equals 1 under $t>0$, which can be written down as:

$$
H(t)=\left\{\begin{array}{ll}
0, & t<0 \\
1, & t \geq 0
\end{array}\right\}
$$
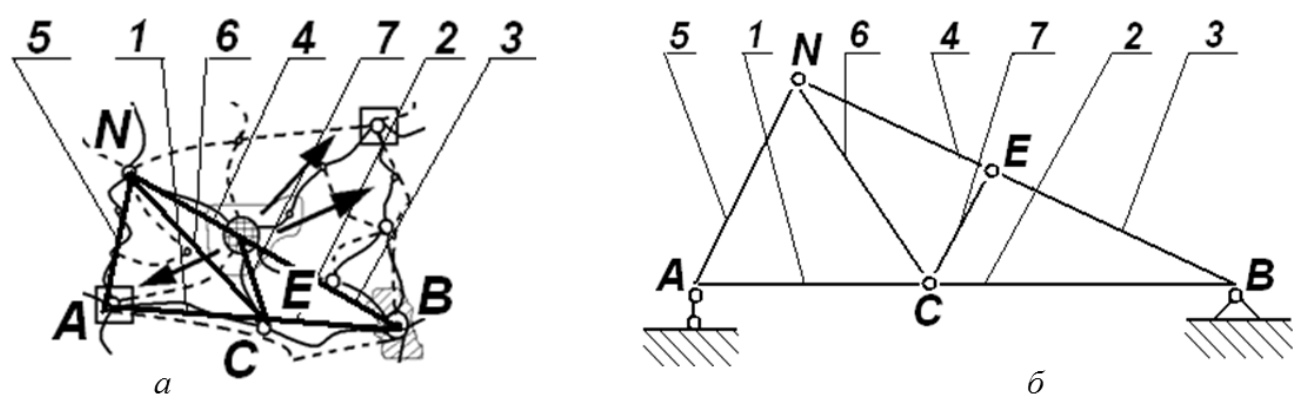

$a$ - the structure of the railways morphology of an agglomeration; $\sigma$ - a virtual model of a supporting framework of an agglomeration; $1,2,3,4,5,6,7$ - the elements of a rod structure of a supporting framework; $A, B, C, N, E$ - the nodes of a rod model of a supporting framework

Figure 4. Virtual modeling of a supporting framework of an agglomeration

It is clear that if we multiply the function $F(t)$ of the external impact by $H(t)$, then all ordinates $F(t)$ under $t<0$ will be missing, and under $t>0$ the ordinates of the function $F(t)$, multiplied by 1 , will keep their value.

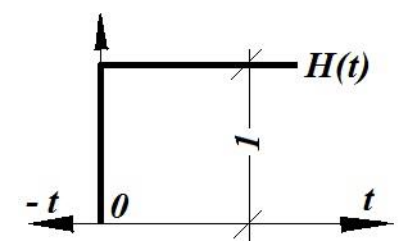

Figure 5. A graph of a unit function (Heaviside unit step function $H(t)$ )

So, the analysis of the dynamics of a supporting framework of NTGES can be virtually reduced to the analysis of some virtual construction of a flat rod truss which is loaded with some forces $H(t)$ (fig. 6). Herewith, to simplify the derivations, it should be mentioned that each of the considered vectors has the value $H / 3$ :

$$
\frac{H}{3}=\frac{H(t)}{3}=\frac{1}{3}
$$

Thus, the analysis of the structural elements reaction of a SF of the NTGES morphology can be reduced to estimating the strength in the construction rods of a flat truss (fig. 6, б), drieven by heaviside unit-step function $H(t)$ (fig. 5).
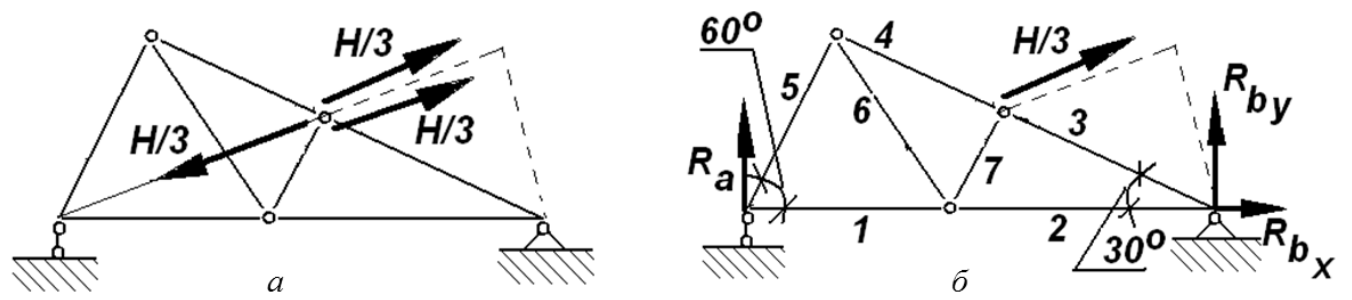

Figure 6. Simulator-models of a supporting framework of the NTGES morphology: $a$ - virtual model-analogue; $\sigma$ - analytic model

At the design stage, it is expedient to compare a few alternative variants of the supporting construction of the territory morphology from the point of view of achieving a maximal level of ecological safety. In our case, the suggestion to develop the agglomeration towards the structural element SE (fig. 7, б) unlike with the mentioned above variant (fig. $6, \sigma)$, can be the alternative variant. 

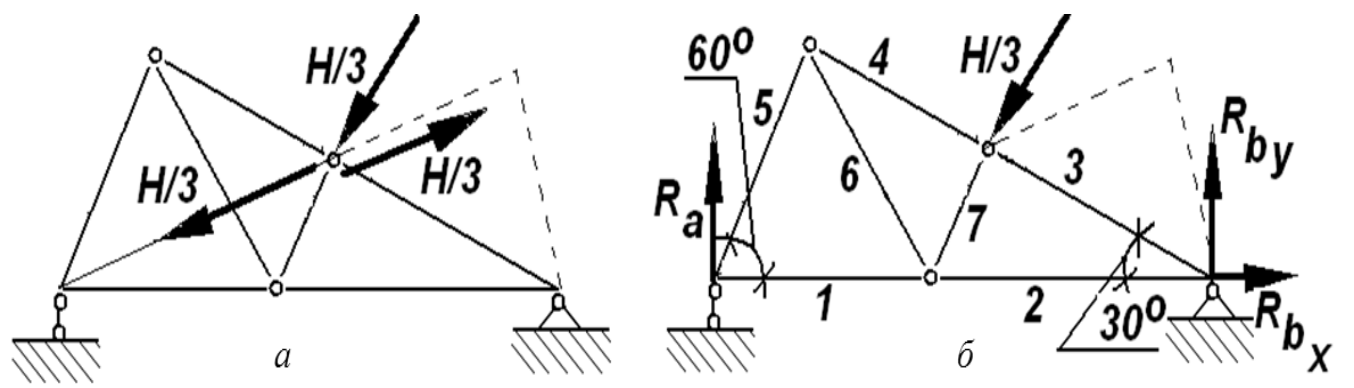

$a$ - an alternative variant of a virtual model-analogue; $\sigma$ - a corresponding analytic model

Figure 7. Models-semulators of a supporting framework of NTGES morphology

The estimation of strength $S_{i}$ in the rods of models-analogues of a supporting framework of NTGES, as a fraction from $H / 3$, is performed by the method of joints or by the method of fixed points (Ritter's method). The results of estimating the strength $S_{i}$ in the rods of the compared models-simulators of the supporting framework of the territory and the value of the averaging strength $S_{\text {aver }}$ in the rods of the compared models-analogues of the supporting framework of the territory and the value of the averaging strength $S_{\text {aver }}$ as some common characteristic of the intensity of the anthropogenic (man-caused) constituent of the NTGES are given in table 1.

Table 1. The results of estimating the strength $S_{i}$ in the rods of the compared models-analogues of a framework and their comparison according to the value $\Delta$

\begin{tabular}{|c|c|c|c|c|c|c|c|c|}
\hline \multirow[t]{2}{*}{ Variant } & \multicolumn{7}{|c|}{ Numerical order of the rods of the model of the supporting framework of the NTGES (fig. 7, б) } & \multirow[b]{2}{*}{$S_{c e p}$} \\
\hline & $S_{1}$ & $S_{2}$ & $S_{3}$ & $S_{4}$ & $S_{5}$ & $S_{6}$ & $S_{7}$ & \\
\hline$S_{I}=f(H)$ & 0.095 & 0.287 & 0.287 & 0.198 & 0.190 & 0.037 & 0.287 & 0.197 \\
\hline$S_{I I}=f(H)$ & 0.083 & 0.167 & 0.221 & 0.172 & 0.167 & 0.033 & 0.333 & 0.167 \\
\hline$\Delta ; \pm \%$ & -12.6 & -42.2 & -23.0 & -13.1 & -12.1 & -10.8 & +16.0 & -15.2 \\
\hline
\end{tabular}

The analysis of the results of the calculation, given in table 1, allows to suppose that the intensity of the impact of an anthropogenic (man-made) constituent on the supporting framework of the NTGES under the alternative variant of an agglomeration development can be reduced on the average by 15-20\% as compared with a base variant, though on some directions (direction EC, in particular) this intensity can rise. Thus, according to the common level of the ecological safety of the territory of the NTGES, the alternative variant of the agglomeration development is the most suitable.

The method of modeling on the principle of electrical dynamic analogues (Vadiunyna and Korchgina, 1986; Yang et al., 2015) can be used as a variant of the suggested technique of virtual modeling of the dynamics of the supporting framework of NTGES. The principle of the method is reduced to the analysis of currents in the electrical circuitry, which imitates the totality of the structural elements of the supporting framework of NTGES. In our case, the electrical circuitry, given in fig. 8, can be suggested as a variant of the electrical dynamic model of the agglomeration framework (fig. 4). Herewith, the nodes of the circuit $A, B, C, N$ correspond to points $A, B, C, N$ of the supporting framework of the agglomeration (fig. 11, a), and the resistors $R_{A C}, R_{C B}, R_{C N}, R_{E C}, R_{B E}, R_{N E}$ imitate the corresponding elements of the rod structure of the NTGES framework.

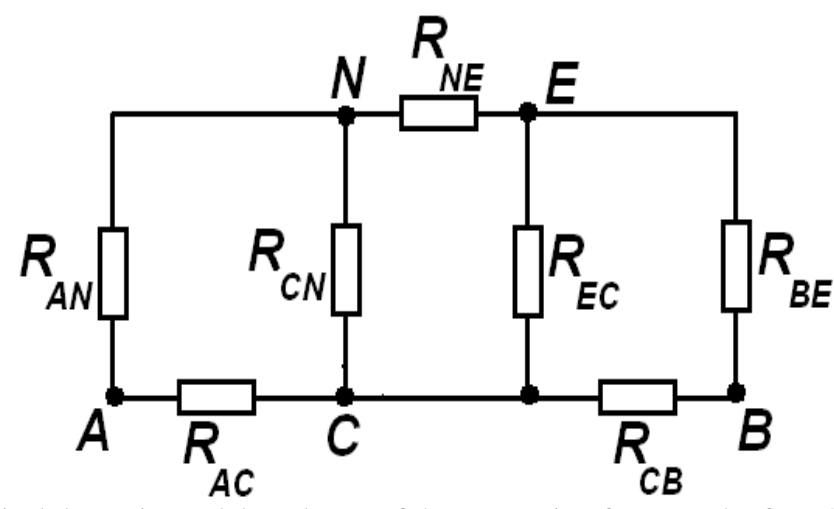

Figure 8. Electrical dynamic model-analogue of the supporting framework of NTGES morphology

The analysis of the suggested electrical dynamic model of the NTGES framework can be made both, analytically (on the basis of Kirchhoff laws (fig. 9, a), and experimentally (by introducing one or more resistors (for example $R_{E C}^{\text {var }}$ in fig. 9, б) into the electrical circuitry). 

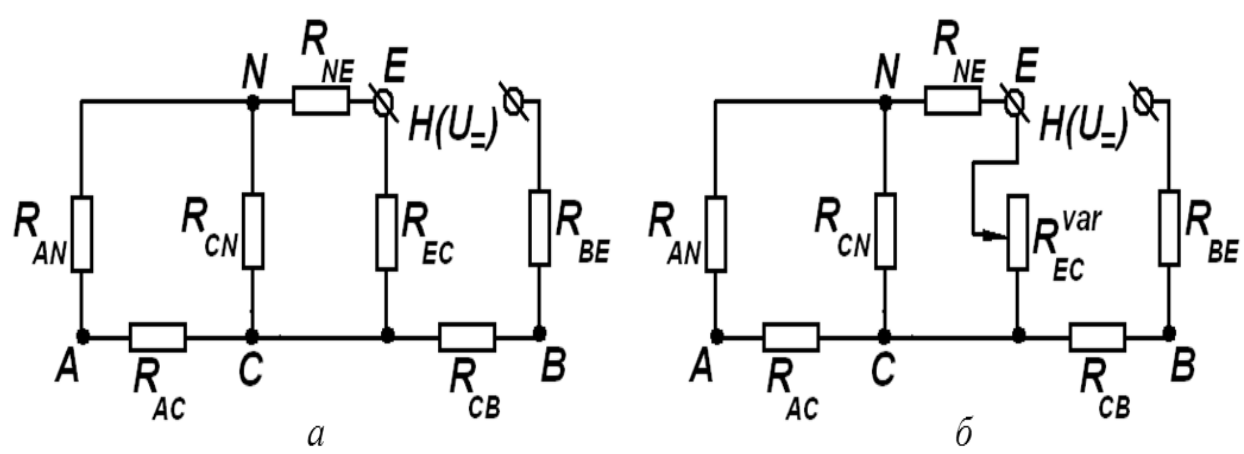

$a$ - the circuitry for analytical analysis; $\sigma$ - the circuitry for experimental analysis

Figure 9. Electrical schematic of the electrical dynamic model-analogue of the supporting framework of NTGES morpholog

On the basis of the second Kirchhoff law (the algebraic sum of electromotive forces (EMF) in a closed circuit, (in our case, it is a model-analogue of a supporting framework of NTGES), equals the algebraic sum of pressure decline in all resistors $R_{A C}, R_{C B}, R_{C N}, R_{E C}, R_{B E}, R_{N E}$ which establish the most suitable level of impact intensity of anthropogenic (manmade) constituent on particular structural elements of the supporting framework of NTGES.

\section{CONCLUSIONS}

1. The suggested model of the analysis of the territorial structure dynamics of natural technogenic geoecosystems under the impact of the anthropogenic constituent by means of virtual models- simulators of the supporting framework of the territory allows (at the design stage of NTGES) to optimize the transformation processes of natural territorial complexes and provide for a maximum possible level of their ecological safety.

2. On the results of the adaptation of mechanical dynamic and electrical dynamic methods of the simulation of compound natural systems, the authors have substantiated the variants of some physical models of the anthropogenic transformation of natural territorial complexes to the condition on natural technogenic geoecosystems, which allow to optimize the managerial decisions as to reducing the levels of technogenic impact on particular nodes and objects of a supporting framework of the territorial structures.

3. The analytical optimization of the alternative variants of transformation of natural territorial complexes allows (on the stage of NTGES design) to reduce the levels of anthropogenic (man-made) impact on them by $15-20 \%$.

\section{REFERENCES}

1. Adamenko O. 2014. Constructive Ecology. Saarbrucken Deutschland, Lambert.

2. Sheludchenko B. 2014. Basic Principles of Designing Natural Anthropogenic Geoecosystems (landscape-territorial aspect). Kamianets-Podilskyi, PSATU. [In Ukrainian]

3. Jongman R. 2002. Homogenisation and fragmentation of the European landscape: Ecological consequences and solutions. Landscape and Urban Planning, Vol. 58, Book 2-4, pp. 211-221. https://doi.org/10.1016/S0169-2046(01)00222-5

4. Adamenko O. 2014. The Technology of Ecological Studies. Geopolitics and Ecogeodynamics of the Regions. Journal of Tavricheskyi National University after V. I. Vernadskyi, Vol. 10, Book 2, pp. 22-28

5. Vadiunyna A., Korchgina Z. 1986. Technique of Studying the Physical properties of the Soil. Agroprompress, Moscow.

6. Cook E. 2002. Landscape structure indices for assessing urban ecological networks. Landscape and Urban Planning, Vol. 58, Book 2, pp. 269-280. https://doi.org/10.1016/S0169-2046(01)00226-2

7. Baidikov I. 2014.Theoretical and Methodological Aspects of Establishing and Substantiating the Landscape Complexes as Potential Constituents of the Framework of an Ecological Network. Ukrainian Geographical Journal, Vol. 2, pp. 51-57. https://doi.org/10.15407/ugz2014.02.051

8. Li F., Ye Y., Song B., Wang R. 2015. Evaluation of urban suitable ecological land based on the minimum cumulative resistance model: A case study from Changzhou, China. Ecological Modelling, Vol. 318, pp. $194-203$. https://doi.org/10.1016/j.ecolmodel.2014.09.002

9. Gorbachova L. 2014. Spacing of the Connections among the Elements of Water Balance of River Water Pools of Ukraine. Ukrainian Geographical Journal, Vol. 2, pp. 17-21. https://doi.org/10.15407/ugz2014.02.017

10. Loibl W., Tötzer T., Köstl M., Steinnocher K. 2007. Simulation of polycentric urban growth dynamics through agents. Modelling Land-Use Change: Progress and Applications, Vol. 90, pp. 219-235. https://doi.org/10.1007/978-1-4020-5648-2 13

11. Rouget M., Cowling R., Pressey R., Richardson D. 2003. Identifying spatial components of ecological and evolutionary processes for regional conservation planning in the Cape Floristic Region, South Africa. Diversity and Distributions, Vol. 9, pp. $191-210$. https://doi.org/10.1046/j.1472-4642.2003.00025.x

12. Mordvinova V., Kobelev M., Treusov M., Khritova A., Trynkova M., Kobeleva D., Lukhneva E. 2016. Deep Structure of a Transition Zone Sibirian Platform - Central Asian Mobile Belt according to Teleseismic Data. Geodynamics \& Tectonophysics, Vol. 7, Book 1, pp. 85-103. https://doi.org/10.5800/GT-2016-7-1-0198 
13. Hussain M., Imitiyaz I. 2018. Urbanization Concepts, Dimensions And Factors. International Journal of Recent Scientific Research, Vol. 9, Book 1, pp. 23513-23523. http://dx.doi.org/10.24327/ijrsr.2018.0901.1483.

14. Gilcrease K. 2013. An Assessment of Leporid Research and Landscape Ecology Metrics in a European Landscape. Journal of Landscape Ecology, Vol. 6, Book 1, pp. 5-11. https://doi.org/10.2478/v10285-012-0060-x

15. Yang T., Jing D., Wang S. 2015. Applying and exploring a new modeling approach of functional connectivity regarding ecological network: A case study on the dynamic lines of space syntax. Ecological Modelling, Vol. 318, pp. 126-137. https://doi.org/10.1016/j.ecolmodel.2014.11.015 